\title{
Pembuatan Website Kumpulan Berita Hoax Untuk Menjaga Kualitas Pesan Pada Ruang Publik
}

\author{
Subarisman $^{1}$, Mohammad Zhofir Ekaputra ${ }^{2}$ \\ ${ }^{1}$ Mahasiswa, STIKOM London School of Public Relations-Jakarta \\ Intiland Tower Lt.6, J1. Jend Sudirman Kav. 32, RT.3/RW.2, Karet Tengsin, Kota Jakarta Pusat, \\ Daerah Khusus Ibukota Jakarta 10250 \\ (tlp: 021-57904365; e-mail: asubarisman@gmail.com) \\ ${ }^{2}$ Mahasiswa, STIKOM London School of Public Relations-Jakarta \\ Intiland Tower Lt.6, J1. Jend Sudirman Kav. 32, RT.3/RW.2, Karet Tengsin, Kota Jakarta Pusat, \\ Daerah Khusus Ibukota Jakarta 10250 \\ (tlp: 021-57904365; e-mail: mohammadzhofir@gmail.com)
}

\begin{abstract}
Technology evolve so rapidly, making the birth of a variety of New Media based on the Internet. New media such as Website, Social Media more and more popping up. New Media should be a positive thing; many traditional media are flocking to create new media or change their media into online media based on the Website. It facilitates the public in finding information anytime anywhere, not limited time and space. Online Media coverage can quickly spread through Social Media as well as through instant messaging services. New Media also changes readers who previously could only enjoy news, can now collaborate or even make a media. It becomes a problem when everyone can create media and pass information through media. Messages or information conveyed are sometimes not in accordance with the real thing or intentionally to make and deliver fake news commonly called Hoax. Hoax are even produced intentionally for the benefit of groups or certain people, Hoax news makes the media as public space contaminated, Habermas calls it Refeudalization, namely that certain groups intervene into the public sphere, in the end the society becomes victims of Hoaxes coverage. To answer this problem, it is necessary to create a media that contains a collection of news of the Hoax with the aim of being a place to clarify news so that the public will not become a victim of Hoax reporting.

Keywords:Website, Hoax, Message, Public Sphere
\end{abstract}

Intisari- Perkembangan teknologi yang begitu pesat, membuat lahirnya bermacam-macam media baru (New Media) yang berbasis Internet. New media seperti Website, Social Media semakin banyak bermunculan. New Media seharusnya bisa menjadi hal yang positif, banyak media traditional yang berbondong-bondong membuat media baru atau merubah medianya menjadi media online yang berbasis Website. Hal itu memudahkan masyarakat dalam mencari informasi bisa kapan saja di mana saja, tidak terbatas waktu dan ruang. Sebuah pemberitaan Media Online bisa cepat menyebar melalui Social Media dan juga melalui layanan pesan instant (messenger). New Media juga merubah pembaca yang tadinya hanya bisa menikmati sajian berita, kini bisa berkolaborasi atau bahkan membuat sebuah media.Hal tersebut menjadi masalah ketika semua orang bisa membuat media dan menyampaikan informasi melalui medianya. Pesan atau informasi yang disampaikan kadang tidak sesuai dengan hal yang sebenarnya atau sengaja untuk membuat dan menyampaikan berita-berita palsu yang biasa disebut Hoax. Hoax bahkan diproduksi dengan sengaja untuk kepentingan kelompok atau orangorang terentu, pemberitaan Hoax membuat media sebagai ruang publik tercemari atau terkontaminasi, Habermas menyebut itu dengan Refodalisasi yaitu bahwa negara dan kelompok-kelompok tertentu melakukan intervensi ke dalam ruang publik, pada akhirnya masyarakatlah yang menjadi korban pemberitaan Hoax. Untuk menjawab permasalahan ini perlu dibuat sebuah media yang berisi kumpulan berita-berita Hoax dengan tujuan sebagai tempat melakukan klarifikasi terhadap sebuah pemberitaan agar masyarakat tidak menjadi korban pemberitaan Hoax. Kata kunci: Website, Hoax, Kualitas Pesan, Ruang Publik

\section{Pendahuluan}

\section{A. Latar Belakang}

Seiring perkembangan teknologi dan Internet yang begitu pesat, infornasi begitu cepat tersampaikan dengan hitungan detik pada ranah Internet, masyarakat bisa dengan cepat dapat menerima informasi. Internet telah menghadirkan ruang publik baru yaitu media atau ruang yang berbasis digital (online) sebagai ruang baru untuk berinteraksi. Pada era ini masyarakat atau publik tidak lagi hanya sekedar menjadi penikmat media, tetapi juga bisa berkolaborasi atau bahkan memiliki media sendiri. Kemunculan publik sebagai pencipta media membuat begitu banyak informasi dengan mudah bisa kita peroleh, karena melalui media yang berbasis Web publik dapat menyampaikan informasi apapun secara luas pada saat ini.

Pertumbuhan media online yang tergolong begitu tinggi, namun hanya beberapa media saja yang telah terverifikasi. Dewan Pers menyatakan, selama 2016 
pertumbuhan media online di Indonesia mencapai sekitar 43 ribu situs. Sekitar 40 ribu media di antaranya belum terverifikasi. Baru 230 saja, sedikitnya media yang terverifikasi, dapat membuat pengakses mendapatkan pemberitaan yang tidak tepat atau bahkan Hoax (Putra, 2017).

Pemberitaan Hoax marak sekali dan mudah beredar pada msayarakat luas akhir-akhir ini, baik melalui social media maupun pesan instan. Maraknya pemberitaan Hoax membuat media online sebagai ruang publik tercemari, informasi yang didapatkan tidak lagi sesuai dengan kejadian yang sebenarnya atau bahkan sengaja dikonstruksi sedemikian rupa untuk tujuan tertentu oleh pihak-pihak yang berkepentingan.

\section{B. Rumusan Masalah}

Pemberitaan Hoax semakin banyak beredar, bagaimana menjadikan berita Hoax pada satu wadah database.

\section{Batasan Penelitian}

Obyek penelitian hanya pada pemberitaan Hoax, informasi yang akan disajikan adalah seputar berita Hoax.

\section{D.Tujuan Penelitian}

Membuat sebuah wadah yang berisi berita Hoax sebagai tempat masyarakat untuk melakukan klarifikasi sebuah pemberitaan.

\section{B. Manfaat Penelitian}

a. Memudahkan masyarakat untuk melakukan klarifikasi pada sebuah pemberitaan.

b. Sebagai database online yang berisi kumpulan berita-berita Hoax.

\section{Tinjauan Pustaka}

\section{A. Ruang Publik}

Ruang publik adalah bagian terpenting pada kehidupan sosial dan dalam bermasyarakat. Ruang publik adalah tempat dimana masyarakat dapat bertemu dan bekumpul melakukan kegiatan serta membicarakan segala hal dalam kehidupan. Konsep ruang publik merupakan bagian vital dari negara yang menjunjung tinggi demokrasi. Demokrasi dapat berjalan dengan baik jika dalam suatu negara terdapat ruang publik yang dimana setiap orang atau warga negara memiliki kesempatan dan juga hak yang sama untuk berpartisipasi dan menyampaikan ide atau pendapatnya (Littlejohn, 2009).

Munculnya Internet telah memunculkan adanya arena ruang publik baru di Indonesia, Cyberspace menawarkan delibrasi terhadap nilai-nilai deliberasi demokrasi baru seperti halnya voluntarisme, egalitarian, maupun juga partisipatorisme (Jati, 2016).

\section{B. Internet}

Menurut Coupey dalam bukunya Marketing and The Internet: Conceptual Foundations, menjelasakan pengertian Internet dalam arti sederhana yaitu komunikasi antara konsumen, marketer, dan jutaan organisasi lainnya. Internet memungkinkan orang untuk menyesuaikan cara mereka berkomunikasi, apakah hanya dengan satu orang atau dengan seluruh target pasar, dengan cepat dan mudah (Coupey, 2011).

\section{Website}

Website adalah kumpulan dari perangkat lunak dan protokol yang sudah melakukan instalasi pada komputer melalui Internet (Sebesta, 2011).

\section{Penelitian Sebelumnya}

Pada penelitian sebelumnya yang dilakukan oleh Bhirawa Anoraga Nandari, Sukadi yang berjudul "Pembuatan Website Portal Berita Desa Jetis Lor", dengan latar belakang bahwa Desa Jetis Lor belum mempunyai sebuah media sebagai sarana untuk menyampaikan pesan. Tujuan pembuatan website tersebut adalah agar seluruh komponen masyarakat mengetahui tentang pengembangan, kemajuan serta keseluruhan tentang komoditas masyarakat, maka perlu dibuat sebuah Website sebagai wadah atau database informasi yang mencakup pada sektor perindustrian, kreatifitas, pertanian dan peternakan di Desa Jetis Lor (Nandari, Sukandi, 2014).

Website adalah sebagai media atau alat untuk menyampaikan pesan secara luas, Suhartanto dengan jurnalnya yang berjudul Pembuatan website sekolah menengah pertama negeri 3 Delanggu dengan 
menggunakan Php dan MySQL mengatakan bahwa pada era sekarang ini hampir semua bidang pada kehidupan ini mempunyai sebuah media online yang berbentuk web sebagai wadah memberikan informasi ataupun untuk edukasi. Website adalah sebuah platform yang berisi dokumen dapat berbentuk teks, gambar, suara ataupun video, yang ditampung dalam sebuah wadah untuk memudahkan seseorang mendapatkan informasi tertentu di dalamnya (Suhartanto, 2012).

Dari kedua hal yang telah dipaparkan di atas, adalah sebagai acuan peneliti untuk membuat Website ini. Perbedaan Website yang dibuat oleh peneliti serta kedua karya tersebut di atas adalah pada informasi yang disampaikan. Website yang dibuat peneliti akan berisi informasi berita-berita Hoax yang telah beredar pada Internet. Dengan tujuan agar masyarakat atau publik bisa mencari kebenaran sebuah pemberitan dengan mencocokan berita yang didapat melalui Website ini. Secara singkat Website yang akan dibuat oleh peneliti berisi berita Hoax agar masyarakat tidak terjebak dan dirugikan dengan adanya informasi-informasi yang tidak benar.

\section{Analisis Dan Pembahasan}

Pemberitaan Hoax marak sekali akhir-akhir ini, apalagi menjelang pemilu dan juga pilkada. Banyak sekali beritaberita dengan konten Hoax yang meresahkan masyarakat. Hoax mudah beredar pada masyarakat dikarenakan teknologi yang berkembang memudahkan masyarakat untuk membagikan ke orang lain tanpa melakukan klarifikasi terlebih dahulu konten berita yang didapatkan. Untuk itu dibutuhkan sebuah media yang berupa Website sebagai tempat untuk mengklarifikasi sebuah pemberitaan. Jika masyarakat mendapatkan sebuah berita, masyarakat bisa melakukan klarifikasi pada Website ini, yaitu dengan mencocokan berita yang didapat. Jika berita tersebut cocok atau sama dengan berita yang berada pada Website ini, maka berita tersebut adalah berita Hoax.

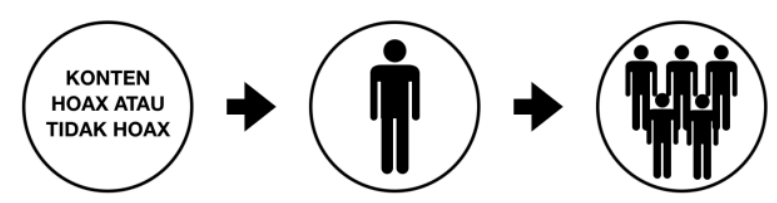

Gambar 1. Kerangka Permasalahan
Gambar 1 adalah bagaimana sebuah konten pada media online baik Hoax atau tidak, jika seseorang mendapatkannya, dengan sangat mudah seseorang membagikan ke orang lain pada era teknologi saat ini. Baik melalui media sosial ataupun pesan instan (broadcast massage).

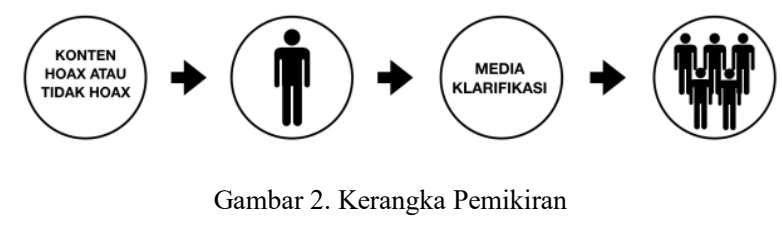

Gambar 2 adalah yang seharusnya jika seseorang medapatkan konten pada media online. Jika seseorang merasa ragu pada sebuah konten yang didapat atau sumbenya tidak jelas agar segera melakukan klarifikasi sebelum membagikan kepada orang lain. Hal tersebut yang seharusnya menurut peneliti akan mengurangi beredarnya berita atau konten-konten Hoax.

Dari kedua hal di atas, yang memacu peneliti ingin membuat sebuah Website sebagai tempat masyarakat untuk melakukan klarifikasi sebuah konten berita. Dengan tujuan agar masyarakat tidak mudah terlena atau bahkan menjadi korban oleh konten-konten Hoax, yang secara sengaja dibuat untuk meresahkan masyarakat. 


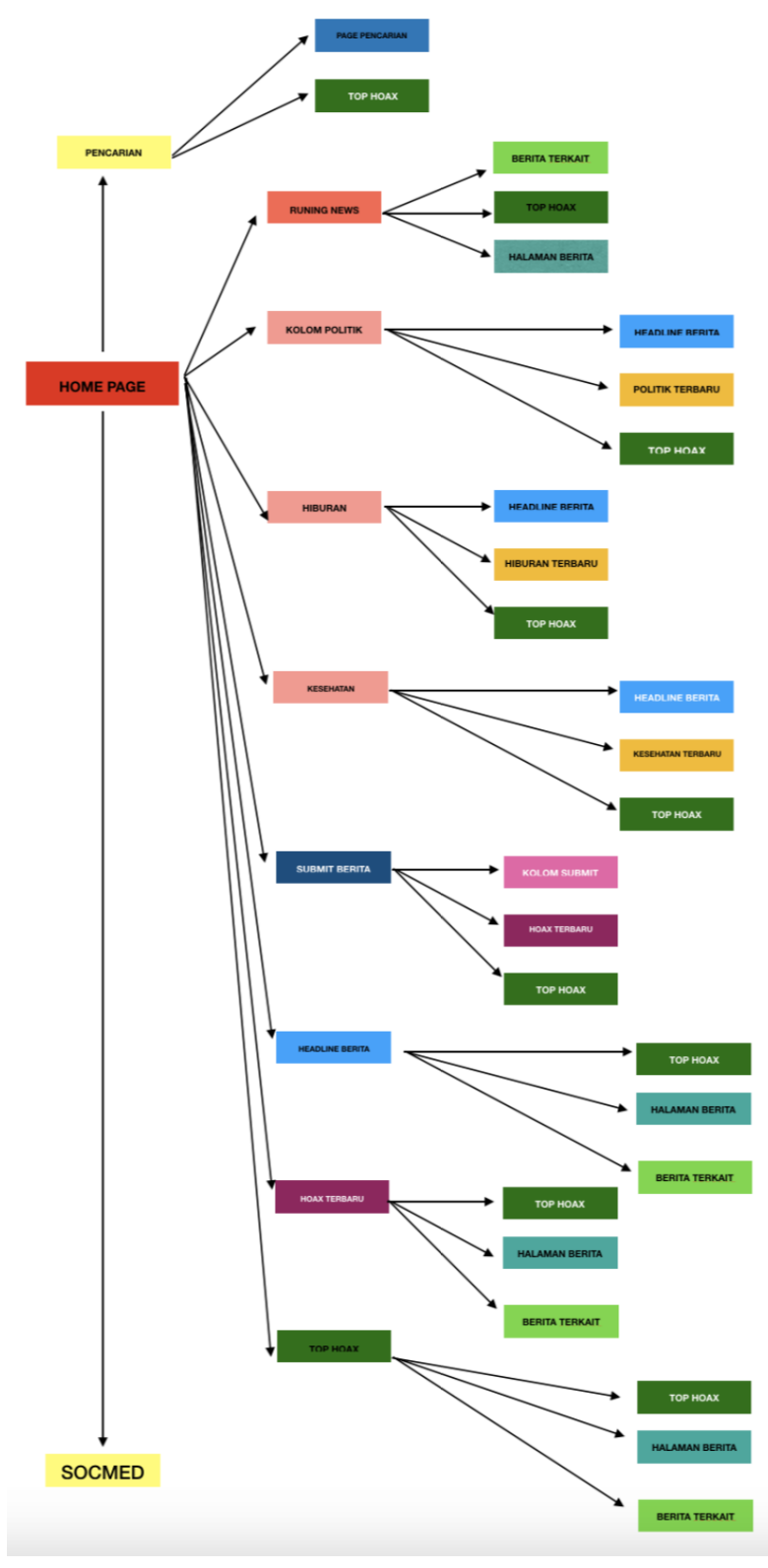

Gambar 3. Anatomi Website

Gambar 3 adalah kerangka atau sistem Website yang akan dibuat oleh peneliti. Penjabaran yang lebih detail mengenai Website yang akan dibuat peneliti, akan peneliti jabarkan pada tahap selanjutnya, yaitu tahap Implementasi.

\section{IV.HASIL DAN IMPLEMENTASI}

\section{A. Konsep dan Nama Website}

Pembuatan website ini secara garis besar hampir sama seperti Yahoo, bekonsep content agregator. Content agregator adalah individu atau organisasi yang mengumpulkan konten Web (dan/atau kadang- kadang aplikasi) dari sumber online yang berbeda untuk digunakan kembali atau dijual kembali (Prilani, 2017).
Secara singkat Website dengan konsep Content agregator adalah website yang berisi bermacam-macam berita yang berasal dari Website lain. Peneliti menggunakan nama Website HOOAXES, dengan tagline "Cek dulu sebelum berbagi”. Nama tersebut juga akan menjadi domain atau alamat Website yang akan dibuat peneliti yaitu www.hooaxes.com. Pengunaan nama dan domain pada sebuah Website adalah bertujuan untuk membedakan Wesbite satu dengan Website yang lain lain, pengertian nama domain yang biasa disebut dengan domain name atau URL adalah sebuah alamat unik yang digunakan pada Internet. Domain name digunakan untuk mengidentifikasi sebuah Website, atau dengan kata lain domain name adalah alamat yang digunakan untuk menuju pada sebuah Website pada Internet.

\section{B. Logo Website}

\section{HOOAXES CEK DULU SEBELUM BERBAGI!}

\author{
Gambar 4. Logo Website
}

Logo yang digunakan pada Website ini adalah tulisan dari nama Website dengan pengunaan double huruf $\mathrm{O}$. Penggunaan double huruf $\mathrm{O}$ dalam nama Website ini dimaksudkan untuk mewakili dan menyerupai kedua mata kita, gambar dua mata juga terdapat dalam logo dari Website ini. Maksud dari penggunaan gambar mata adalah agar kita selalu waspada terhadap sebuah konten pemberitaan, mengajak audience untuk memperhatikan dan menganalisa secara teliti apa yang dibaca atau yang dikonsumsi pada media oleh kedua mata kita.

\section{Klasifikasi Konten}

Konten pada Website ini akan diklasifikasikan kedelalam beberapa klasifikasi, yaitu kolom hiburan, politik \& kesehatan. Kolom hiburan akan berisi kontenkonten Hoax seputar dunia hiburan atau Hoax yang terjadi dalam kehidupan social dalam masyarakat sehari-hari. Konten dalam kolom politik akan berisi konten Hoax septuar dunia perpolitikan di Indonesia. Sedangakan kolom kesehatan akan berisi konten septuar kesehatan seperti makan, obat dan lain-lain. Tidak hanya itu, pada 
Website ini pengunjung juga dapat berpartisipasi untuk mengirimkan berita Hoax yang didapat melalui kolom yang sudah disediakan. Untuk memudahkan mencari berita Hoax, pada Website ini juga disediakan kolom pencarian pada bagian atas dari Website ini.

\section{Target Pengunjung}

Tabel Target yang ingin disasar oleh peneliti atau audience yang diharapkan mengujungi Website ini adalah sebagai berikut:

\section{Geographic}

Secara Geographic peneliti ingin agar Website ini dapat dikunjungi oleh masyarakat diseluruh Indonesia yang sudah terjangkau oleh Internet diantaranya kota Jakarta, Bandung, Jogjakarta, Surabaya, Palembang serta kota- kota besar lainnya. Tidak hanya masyarakat perkotaan, masyarakat desa yang sudah tersambung dengan Internet juga diharapkan menjadi target pengunjung Website ini.

\section{Demographic}

Secara Demographic target pembaca yang akan disasar oleh Website ini dijabarkan sebagai berikut:

- $\quad$ Gender : Male \& Female

- Age : 17-40 Tahun

- Occupation: Students, Collage, Employees

- $\quad$ Education : SD, SMP, SMA \& S1

- $\quad$ SES: A, B \& C

\section{Physcographic}

Secara Physcographic target pembaca yang akan disasar oleh Website ini dijabarkan sebagai berikut: Lifestyle: Experiencers \& Sharing - Hobby : News Reading, Social Media (User and Explorer) - Attitude : Explorer - Behavior : Orang yang suka akan seputar halhal baru, senang mengamati sekitar melalui media, senang membaca berita-berita terbaru dan berbagi berita dengan yang lain.

\section{E. Visualisasi}

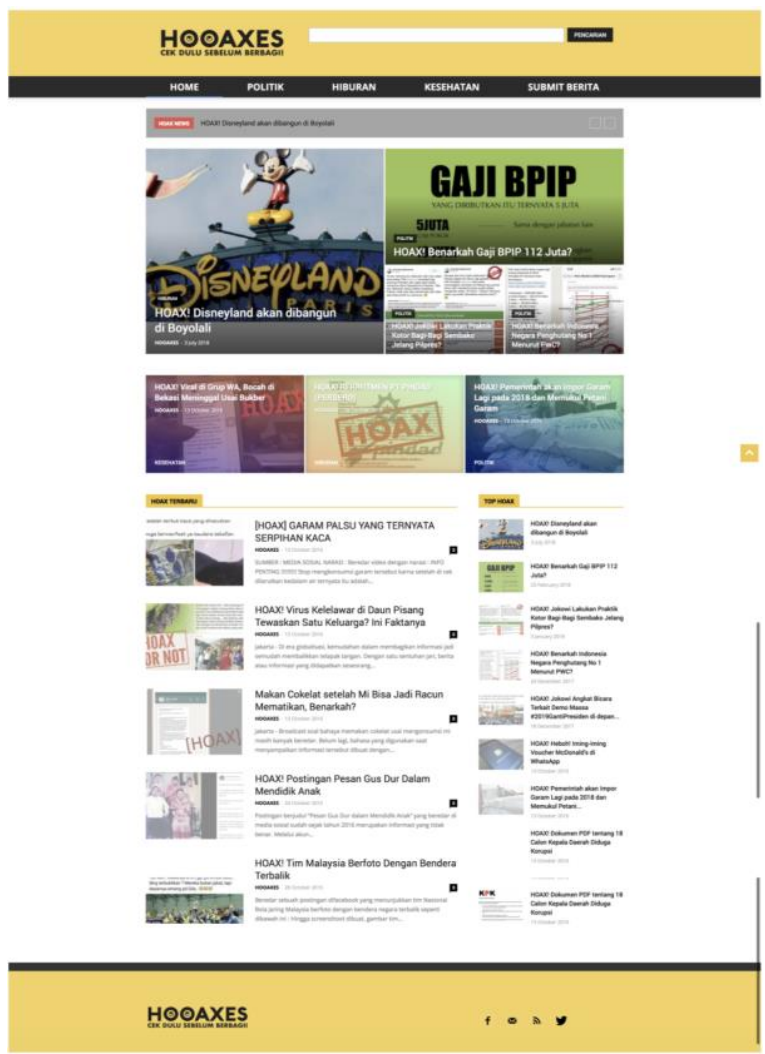

Gambar 5. Tampilan Home Page

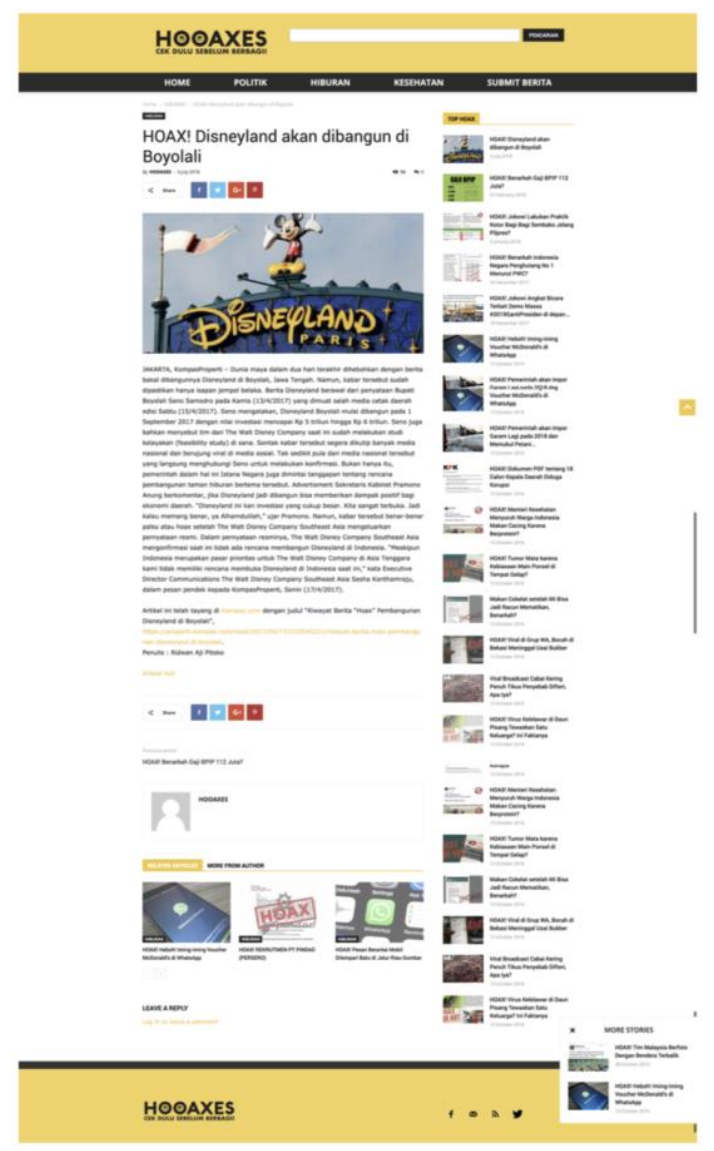




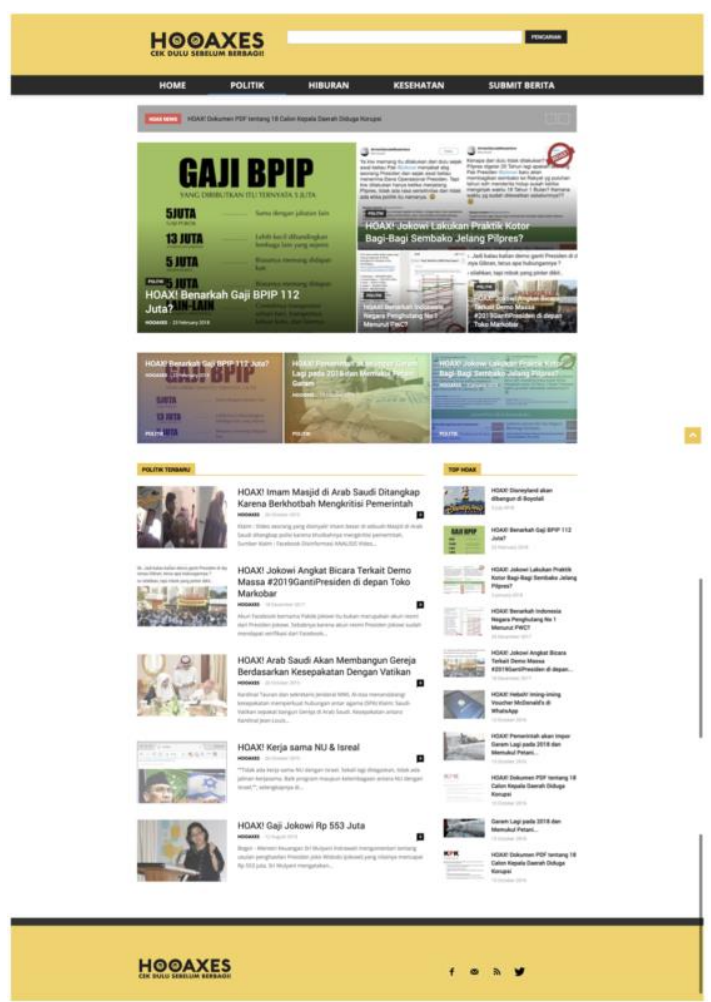

Gambar 7. Tampilan Menu Politik

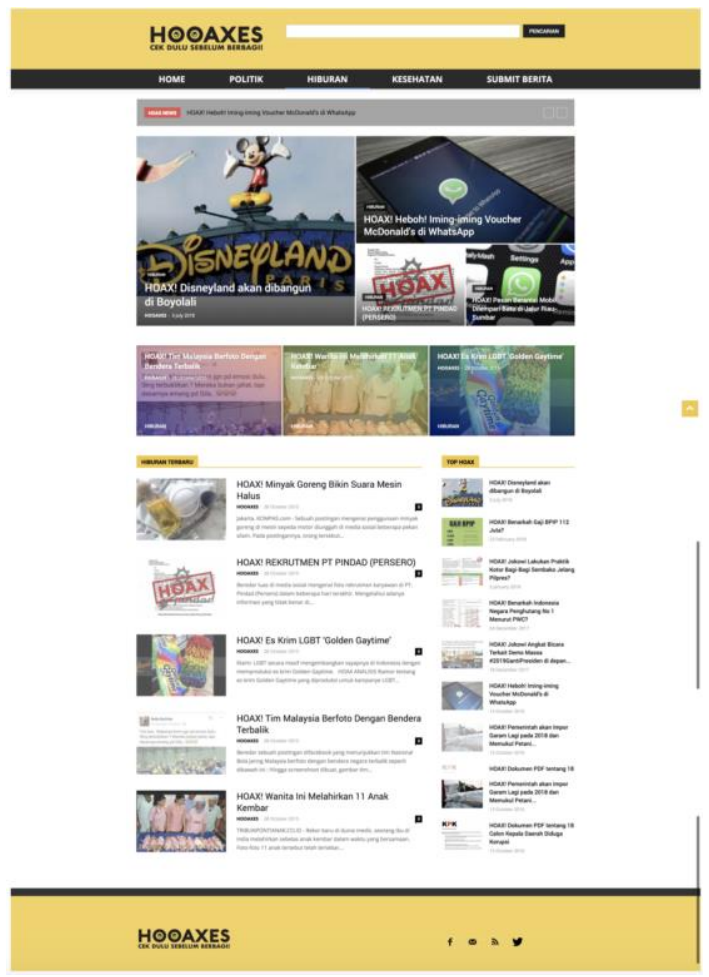

Gambar 8. Tampilan Menu Hiburan

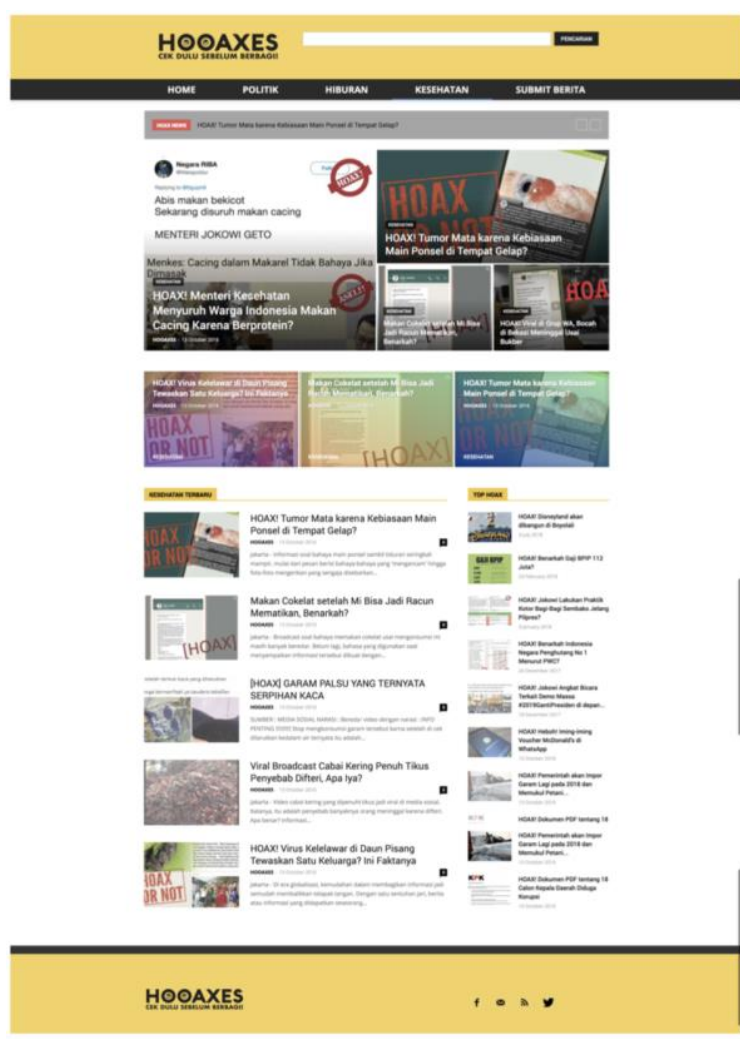

Gambar 9. Tampilan Menu Kesehatan

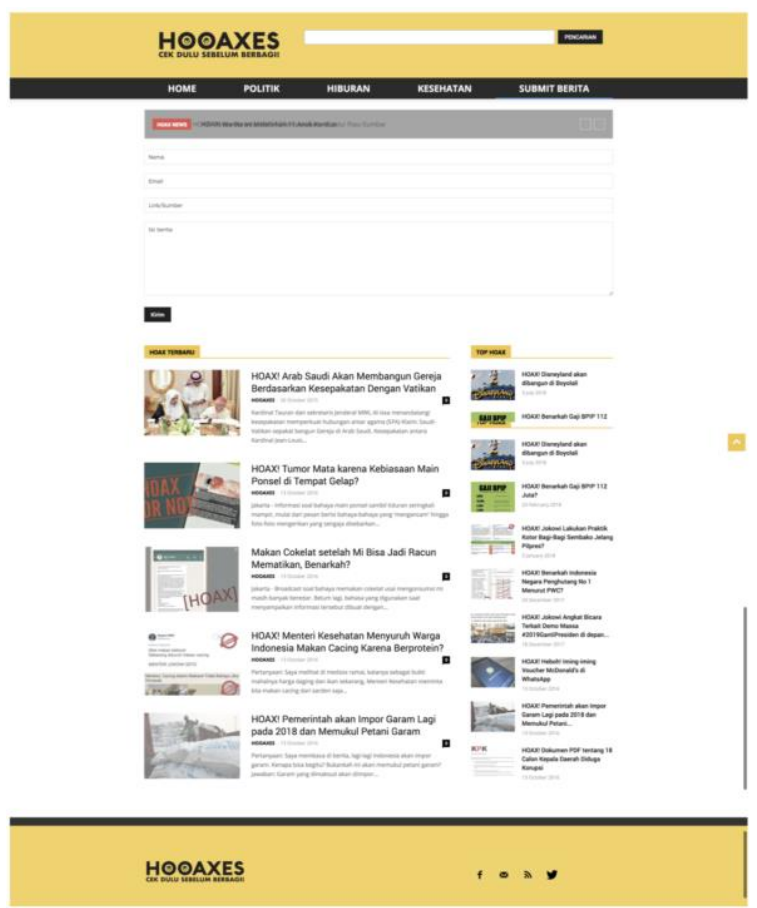

Gambar 10. Tampilan Submit Berita 


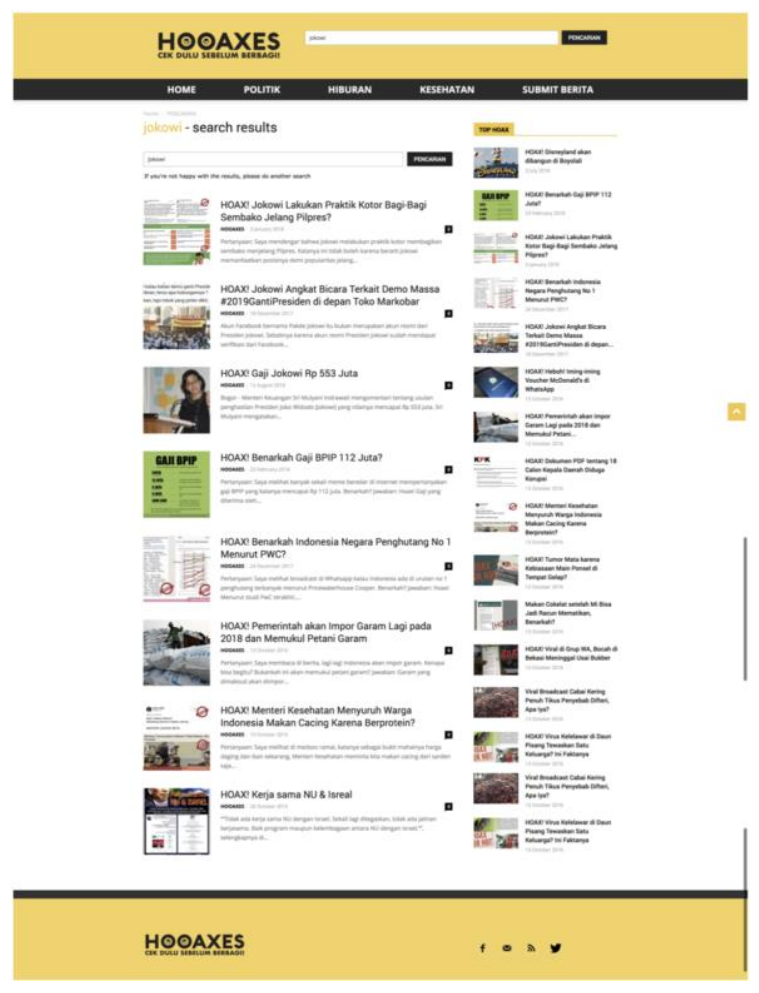

Gambar 11. Tampilan Kolom Pencarian

\section{KESIMPULAN}

\section{A. Implikasi}

Pembuatan Website yang berisi kumpulan berita-berita Hoax adalah bertujuan untuk membantu pemerintah dan masyarakat dalam memerangi berita Hoax. Hoax engine atau Website ini memberikan kemudahan masyarakat dalam mencari kebenaran sebuah berita, sehingga pesan atau informasi yang disampaikan media-media online terjaga kualitasnya, sesuai dengan fenomena atau kejadian yang sebenarnya. Seperti yang sudah kita lihat bahwa pemberitaan Hoax di Indonesia semakin banyak dengan tujuan-tujuan yang selipkan di dalamnya.

Peneliti berharap karya ini dapat membantu dan dipakai oleh masyarakat untuk turut serta memerangi Hoax, sealur dengan tujuan pemerintah untuk memberantas Hoax yang selama ini menghantui masyarakat luas.

\section{B. Rekomendasi}

Dengan adanya Website ini tentunya tidak hanya sampai disini, kedepannya Website ini akan terus di lakukan maintance serta pengembangan-pengembangan seperti penambahan klasifikasi konten dan juga penambahan forum, dimana dengan adanya forum pengunjung akan dapat bersama-sama melakukan klarifikasi sebuah pemberitaan apakah sebuah pemberitaan itu Hoax ataupun tidak. Tujuan dari rekomendasi ini adalah agar Website ini kedepannya akan lebih besar, dari segi pengunjung dan juga dari segi konten-konten yang disajikan. Website ini juga menjadi harapan peneliti untuk dijadikan rekomendasi oleh pemerintah ataupun masyarakat dalam melakukan klarifikasi sebuah pemberitaan juga memerangi berdarnya berita Hoax.

\section{DAFTAR PUSTAKa}

[1] Coupey, E. (2001). Marketing and the internet: Conceptual foundations. Prentice Hall.

[2] Jati, W.R. (2012). Cyberpsace, Internet dan Ruang Publik Baru: Aktivisme Online Politik Kelas Menengah Indonesia. Jurnal Pemikiran Sosiologi, 3(1), 25-35. Retrived from https://journal.ugm.ac.id/jps/article/view/2354

[3] Littlejohn, S. W. \& Foss, K.A. (2009). Encyclopedia of communication theory. California: Sage Publications.

[4] Prilani. (2017). Content agregator: Problem etis jurnalisme online Indonesia. Jurnal Nomosleca, 3(1), 515-525. Retrived from http://jurnal.unmer.ac.id/index.php/n/article/view/1483/946

[5] Putra, N. P. (2017, April 26). Dewan Pers ungkap 40 ribuan media di Indonesia belum terverfikasi. Retrieved from the Liputan6 Website: http://www.liputan6.com/news/read/2932527/ dewan-pers-ungkap-40-ribuan-media-di-indonesia-belumterverfikasi

[6] Sebesta, R. W. (2011). Programming the World wide web. Pearson Education, Inc, USA.

[7] Suhartanto, M. (2012). Pembuatan website sekolah menengah pertama negeri 3 Delanggu dengan menggunakan $\mathrm{Php}$ dan MySQL. Jurnal Speed Sentra Penelitian Engineering dan Edukasi, 4(1), 01-08. Retrived from http://ijns.org/journal/ index.php/speed/article/view/1156 